\title{
Undergraduate nursing students' perceptions of educational service quality at Alexandria University, Egypt
}

\author{
Naglaa Abd El-Aziz El Seesy*1, Rehab Gamel Hussein ${ }^{1}$, Ahlam Eidah Alzahrani ${ }^{2}$ \\ ${ }^{1}$ Faculty of Nursing, Alexandria University, Alexandria, Egypt \\ ${ }^{2}$ Faculty of Nursing, King Abdulaziz University, Jeddah, Makkah, Saudi Arabia
}

Received: May 16, 2017

Accepted: August 1, 2017

Online Published: August 28, 2017

DOI: $10.5430 /$ jnep.v8n1p37

URL: https://doi.org/10.5430/jnep.v8n1p37

\begin{abstract}
This study investigated nursing students' perceptions towards educational service quality provided by specialty departments at the Faculty of Nursing, Alexandria University. It also identified barriers and offers recommendations for improvement. A cross-sectional descriptive design was carried out utilizing a SERVPERF-based survey developed by Cronin and Taylor (1992) to measure students' perceptions towards educational service quality. The participants' responses to the reliability dimension (75.5 \pm SD 12.7) were the highest scoring, while participants' perceptions to the tangibles dimension were the lowest $(61.0 \pm \mathrm{SD}$ 17.5). Further, students' opinions regarding barriers to quality services were related to "limited time for study" and "inadequate equipment for clinical training". Responses to positive factors affecting the quality of services were "accuracy of work", "effective communication", and "gaining new knowledge", as perceived by students. The highest perceived service quality dimension among students was reliability followed by assurance, empathy, responsiveness, and tangibles. Moreover, the majority of students expressed that the Faculty of Nursing gave them prestige in the community, they were happy to study nursing, and they would not study in another higher educational institution even if they had an opportunity to do so.
\end{abstract}

Key Words: Educational service quality, Higher education, Student

\section{INTRODUCTION}

Assessing student perceptions of services and facilities at higher educational institutions has gained popularity in recent years. ${ }^{[1]}$ DeShields et al. $(2005)^{[2]}$ explained that delivering higher quality educational services is the only way for higher educational institutions to successfully compete in the service environment. Service quality has been defined in various terms. O'Neill and Palmer (2004) ${ }^{[3]}$ defined service quality as "the difference between what a student expects to receive and perceived". The level of service quality can be estimated by how much the provided service surpasses stu- dents' expectations. ${ }^{[4]}$ Accurate and efficient assessment of service quality is essential to higher educational institutions that seek to highlight their services in marketing efforts. ${ }^{[5]}$

At present, due to a highly competitive environment in the higher education sector, quality departments are tasked with developing quality management programs to survey and estimate student perception regarding the quality of services provided. In creating these programs, quality departments must consider that patterns influence the quality of scholastic products, and what was a noteworthy concentration of study in the past is not necessarily the most popular concentration

\footnotetext{
*Correspondence: Naglaa Abd El-Aziz El Seesy; Email: nona20102002@yahoo.com; Address: Faculty of Nursing, Alexandria University, Alexandria, Egypt.
}

Published by Sciedu Press 
of study in advanced education today. ${ }^{[6]}$ Some higher educational institutions now endeavor to quantify and enhance service quality through the adoption of Total Quality Management (TQM) techniques and the achievement of quality awards. $^{[7]}$

Due to growing enthusiasm for service quality, a number of tools and strategies have been created to estimate or calculate service quality and customer satisfaction within educational organizations. ${ }^{[8]}$ SERVQUAL is the most popular instrument for appraisal and estimation of perceived quality. Older versions of SERVQUAL have been scrutinized, and improvements and modifications have been made. The aim of SERVQUAL is to identify expectations and perceptions of institutional service quality. However, using only one tool would not adequately identify the gap between expected and perceived quality. ${ }^{[9]}$ Therefore, Cronin and Taylor (1992) ${ }^{[10]}$ created and tested a new instrument called SERVPERF which measures performance only.

A literature review revealed that SERVQUAL has been used in research to quantify service quality in higher educational institutions in countries such as Singapore, Malaysia, Brazil, Croatia, Pakistan, Iran, Indonesia, Thailand, and Jordan. A study conducted by Tan and Kek $(2004)^{[11]}$ which assessed student satisfaction at Singapore University emphasized the need to consider cultural factors when developing SERVQUAL questionnaires. Abu Hasan et al. (2008) ${ }^{[12]}$ studied service quality in private education institutions in Malaysia and found that assurance, empathy, reliability, responsiveness, and tangibility are the five key dimensions to evaluate. They found that the highest perceived service quality dimensions, listed from highest to lowest, are empathy, assurance, tangibles, responsiveness, and reliability, respectively.

A study conducted by DeOliviera and Fereira (2009) ${ }^{[13]}$ in Brazil utilized SERVQUAL to distinguish inconsistencies between what the students expected and what they perceived by modifying the SERVQUAL original scale for the higher education sector. Legčević (2009) ${ }^{[14]}$ studied students' service quality expectations and perceptions at the Faculty of Law at Osijek University in Croatia and reported that students' expectations exceeded their perceptions. Notably, the slightest and most negative errors were related to the reliability and empathy dimensions. Moreover, there were significant differences between expectations and perceptions in all dimensions.

In Pakistan, Zeshan et al. (2010) ${ }^{[15]}$ assessed service quality among eight business schools and found that students perceived low quality in all dimensions in all institutions. Similarly, Khodayari and Khodayari (2011 ${ }^{[16]}$ examined the expectations and perceptions of Islamic Azad University in Iran and found a discrepancy between what was expected and perceived by students in all dimensions of service quality. Further, Amelia et al. (2011) ${ }^{[17]}$ reported that a study of quality of service in Indonesia found discrepancies between expectations and service performance with the highest in the reliability dimension and the lowest in the assurance dimension. Therefore, improvements to service quality lead to increased student satisfaction.

Mohamad Yusuf et al. (2012) ${ }^{[18]}$ studied service quality in higher education and found that the tangibles dimension was the most important dimension reported, whereas empathy and assurance were least important. The results of this review can help scholastics and administrators allocate their resources more effectively. For instance, Al-Alak and Alnaser $(2012)^{[19]}$ have suggested that the assurance and reliability dimensions should be prioritized for improvement.

Middle Eastern countries are expanding their higher educational organizations due to growing social, fiscal, and administrative demands. To improve advanced education, different methodologies have been adopted, including moving to the private sector. Most Arab countries have used the private sector approach to tackle increased demand and improve service quality. Although accreditation has helped evaluate the quality of institutions, negative feedback is the main evaluating factor of service quality for higher educational institutions used in Middle Eastern countries. ${ }^{[20]}$

Egyptian higher educational institutions have seen a similar reliance on negative feedback despite the fact that Egypt has some of the most prestigious colleges in the Middle East and Africa. ${ }^{[21,22]}$ The Ministry of Higher Education in Egypt has experienced a decline in the quality of training offered in Egyptian institutions. ${ }^{[23,24]}$ This decline has been caused by three main issues which affect education, inadequate educational resources, curricula, and academic freedom. ${ }^{[25]}$

The principle purpose of this study is to identify and understand nursing students' perceptions at Alexandria University, which historically has been one of the most prestigious higher educational institutions in Egypt. This study surveys and measures student perception of service quality, identifies barriers, and offers recommendations for improvement. The findings are intended to provide useful insights of use to both academic managers and policy makers in resource planning and strategy implementation.

\section{METHOD}

\subsection{Participants}

The participants in this study were 525 undergraduate nursing students who were studying in one of the following eight 
specialty academic nursing departments in the Faculty of Nursing at Alexandria University: medical and surgical; critical care; pediatric; obstetrics and gynecology; community health; geriatric; psychiatric and mental health; and administration.

\subsection{Study design}

This study used a cross-sectional descriptive design. A SERVPERF-based survey was used. It consisted of 20 items grouped into the following five dimensions: reliability (seven items); assurance (four items); responsiveness (five items); tangibles (three items); and empathy (one item). Students' responses were assessed using a Likert scale ranging from strongly agree (5) to strongly disagree (1). Negative items were given reverse scores. Higher scores indicated that the specialty departments were offering high service quality.

In addition to the survey, seven closed-ended questions required respondents to answer yes or no. Examples of these questions include the following: "Do you agree that allocated course requirements are fair for the fifteen-week term?"; "Do you agree that the nursing program should include oral exams?" and "Overall are you happy studying at the Faculty of Nursing?" The study also included questions related to the nursing students' socio-demographic characteristics, such as age, sex, permanent residence, previous educational level, current nursing specialty, work during the study, and previous failure in nursing specialties. Furthermore, open-ended questions related to positive (facilitating) factors, barriers, and recommendations for improvement of the quality of the educational services provided.

\subsection{Data collection}

The Ethics Committee of the Faculty of Nursing, Alexandria University approved the study protocol. They determined that the survey used in this research did not fall under the committee's jurisdiction. The SERVPERF-based survey was translated into Arabic and validated by five specialized faculty staff. In addition, the reliability of the tool was tested using Cronbach's alpha coefficient test.

Before beginning data collection, informed consent was obtained from each student for participation in this study. All participants were assured that their participation was voluntary. Also, their privacy and confidentiality were maintained. A pilot study was carried out on $10 \%$ of the participants. The questionnaire was hand delivered to each study participant.

The survey was completed through a self-report method. Each participant was allowed 20 minutes to complete the questionnaire. Data collection took from May 2013 until
March 2014. All statistical analysis was done utilizing students t-test and One-Way ANOVA using statistical software SPSS version 20. Internal consistency for the scale was tested using alpha Cronbach's, while Correlation coefficient was used to identify the nature and the degree of relation between scale domains.

\section{Results}

Between May 2013 and March 2014, a total of 525 undergraduate nursing students successfully consented to and completed the questionnaires, with an average response rate reaching $52.8 \%$. Received responses were classified according to each participant's specialty including medical and surgical $(n=179)$, critical care $(n=59)$, pediatric $(n=60)$, obstetrics and gynecology $(n=69)$, community health $(n=$ $31)$, geriatric $(n=21)$, psychiatric and mental health $(n=61)$, and administration $(\mathrm{n}=45)$.

About one-half of the undergraduate nursing students ranged from 20 to less than 22 years old. While $77 \%$ of the undergraduate nursing students were female, $91 \%$ were residents of rural areas, and $73.3 \%$ had the previous qualification of a secondary school certificate.

The medical-surgical nursing department represented the highest number of undergraduate nursing students (34.1\%) followed by the obstetrics and gynecology department $(13.1 \%)$. Moreover, more than two-thirds of nursing students $(69.1 \%)$ were working during their study at the university, and $78.3 \%$ of nursing students had not previously failed in any nursing specialties.

The overall mean score of perception of service quality was $70.9 \pm$ SD 10.3. In addition, the highest scoring of participants' perceptions was found on their responses to the reliability dimension (75.5 \pm SD 12.7), while participants' perceptions to the tangibles dimension was the least perceived item (61.0 \pm SD 17.5) (see Table 1).

The mean scores of the underlying items of the reliability dimension ranged from 3.52 to 3.94. The highest scoring of participants' perceptions regarding the reliability dimension were found in their responses to the following items: "Academics staff are ready to provide individual attention for their students during their consultation session" (3.94 \pm SD .896); "The department offers its services within the expected time" (3.88 \pm SD .823); and "The department deals with queries quickly and efficiently" (3.87 \pm SD .957). By comparison, the lowest scoring of participants' perceptions regarding the reliability dimension were found in their responses to "Administrative staff in the department are interested in solving problems" (3.52 \pm SD 1.067) (see Table 2). 
Table 1. Mean scores percentages of nursing students' perception of service quality dimensions at the scientific departments at the Faculty of Nursing, Alexandria University

\begin{tabular}{lllll}
\hline Service quality dimensions & Minimum & Maximum & Mean (\%) & SD \\
\hline Reliability & 20.0 & 100.0 & 75.5 & 12.7 \\
Assurance & 20.0 & 100.0 & 73.6 & 15.6 \\
Responsiveness & 36.0 & 100.0 & 71.4 & 12.0 \\
Tangible & 20.0 & 100.0 & 61.0 & 17.5 \\
Empathy & 20.0 & 100.0 & 71.8 & 18.4 \\
Social value & 20.0 & 100.0 & 63.5 & 11.6 \\
Functional value and want satisfaction & 20.0 & 100.0 & 72.5 & 16.6 \\
Overall service quality & 29.2 & 99.2 & 70.9 & 10.3 \\
\hline
\end{tabular}

Table 2. Mean scores of nursing students' perception of service quality dimensions' sub items at the scientific departments at the Faculty of Nursing, Alexandria University

\begin{tabular}{|c|c|c|}
\hline Service quality items & Mean & SD \\
\hline \multicolumn{3}{|l|}{ Reliability: } \\
\hline 1. The department offers its services within the expected time. & 3.88 & .823 \\
\hline 2. The department dealt with queries quickly and efficiently. & 3.87 & .957 \\
\hline 3. Administrative staff in the department are interested in solving problem I have. & 3.52 & 1.067 \\
\hline 4. Administration of the department keeps accurate records & 3.77 & .872 \\
\hline 5. Services in the department are performed right the first time. & 3.62 & 941 \\
\hline 6. When the administrative staff in the department promise to do something by a certain time they do so. & 3.84 & .931 \\
\hline 7. Academics staff are ready to provide individual attention for their students during their consultation session. & 3.94 & .896 \\
\hline \multicolumn{3}{|l|}{ Assurance: } \\
\hline 1. Academic staff has the required knowledge to reply on my questions in regards courses given. & 4.05 & 850 \\
\hline 2. Academic staff able to understands their students’ needs. & 3.51 & 1.059 \\
\hline 3. All staff in the department are consistently courteous to me. & 3.57 & 1.033 \\
\hline 4. The department allowed me to feel secure in my academic transactions. & 3.60 & 1.008 \\
\hline \multicolumn{3}{|l|}{ Responsiveness: } \\
\hline 1. All staff in the department are never too busy to respond to a request for assistance. & 3.38 & 1.027 \\
\hline 2. I have confidence on academic staff who employs on this department. & 3.91 & .850 \\
\hline 3. I have confidence on support staff who employs in this department. & 3.79 & .867 \\
\hline 4. Academic staff are not willing to provide help for their students in the department. & 2.59 & 1.119 \\
\hline 5. Support staff have no willingness to provide help for their students. & 2.63 & 1.139 \\
\hline \multicolumn{3}{|l|}{ Tangible: } \\
\hline 1. The physical facilities are visually appealing. (i.e., building and surroundings). & 3.08 & 1.221 \\
\hline 2. Course materials such as books, boards, and data show etc.) are attractive. & 3.09 & 1.195 \\
\hline 3. The available equipment in the department are updated. & 2.98 & 1.083 \\
\hline \multicolumn{3}{|l|}{ Empathy: } \\
\hline 1. Academic staff treated me in a caring way & 3.59 & .918 \\
\hline \multicolumn{3}{|l|}{ Social value: } \\
\hline 1. The caliber of your classmates enhance the learning process & 3.53 & .976 \\
\hline 2. You feel your colleagues focus on individual achievement over teamwork & 3.46 & 1.038 \\
\hline 3. The interpersonal skills stressed in the curriculum such as communication ,motivation, etc. & 3.45 & 1.026 \\
\hline \multicolumn{3}{|l|}{ Functional value and want satisfaction: } \\
\hline 1. The department prepare you for a successful career in business & 3.68 & 1.038 \\
\hline 2. I have handed with practical information which was usable in at beginning of my job. & 3.77 & .946 \\
\hline 3. Network and connections that available in the department help me throughout my career. & 3.42 & 1.063 \\
\hline
\end{tabular}

Furthermore, "Academic staff has the required knowledge to reply on my questions in regard to the given courses" and "The department allowed me to feel secure in my academic transactions" had the highest mean scores among the items in the assurance dimension which ranged from 3.51 to 4.05 . The least perceived item was "Academic staff able to under- 
stand their students' needs" (3.51 \pm SD 1.059).

Moreover, the mean scores of the responsiveness dimension ranged from 2.59 to 3.9. The highest scoring of participants' perceptions regarding the responsiveness dimension were found in their responses to "I have confidence in academic staff who employs on this department" and "I have confidence in support staff who employs in this department", $(3.91 \pm \mathrm{SD} .850)$ and (3.79 \pm SD .867), respectively. While the lowest scoring belongs to "Academic staff are not willing to provide help for their students in the department" $(2.59 \pm$ SD 1.119).

The tangibles dimension represented the lowest mean score among the quality dimensions and ranged from 2.98 to 3.09. The highest scoring item in this dimension was "Course materials such as books, boards, data show etc. are attractive" (3.09 \pm SD 1.195), and the lowest scoring item was "The available equipment in the department are updated" (2.98 $\pm \mathrm{SD} 1.083)$. The empathy dimension consisted of a single item, "Academic staff treated me in a caring way", and it had a mean score of (3.59 \pm SD .918).

Regarding department specific questions, the mean scores of the social value dimension ranged from 3.53 to 3.45 . The highest scoring of participants' perceptions regarding the social value dimension were found in their responses to "The caliber of your classmates enhances the learning process"
(3.53 \pm SD.976). The lowest scoring belonged to "The interpersonal skills stressed in the curriculum such as communication, motivation" (3.45 \pm SD 1.026).

In addition, the mean scores of the functional value and want satisfaction dimension ranged from 3.68 to 3.42 . It is noted that "I have handed with practical information which was usable in at beginning of my job" had the highest mean score among the items of the functional value and want satisfaction dimension (3.68 \pm SD 1.038). "Network and connections that available in the department help me throughout my career" had the lowest mean score among the items in this dimension (3.42 \pm SD 1.063).

The male nursing students' mean score percentage (74.1 \pm SD 9.8) was higher than the females (69.9 \pm SD 10.3) when it came to their perceptions of the overall quality of services $(p<.001)$. Further, students' perceptions of service quality differed significantly between age groups. The highest perception of quality services was for students aged 18 to less than 20 years old. Also, there was a significant difference among nursing students' mean percentage scores in relation to nursing specialties $(p<.001)$. Students studying pediatric, medical-surgical, geriatric, and psychiatric and mental health nursing had the highest perception of quality of services compared to students who studied nursing administration (see Table 3).

Table 3. Mean scores percentages of overall nursing students' perception of service quality in relation to their demographic characteristics

\begin{tabular}{|c|c|c|c|c|}
\hline \multirow{2}{*}{ Demographic characteristic } & & \multicolumn{2}{|c|}{ Overall service quality } & \multirow{2}{*}{$P / t$} \\
\hline & & Mean & SD & \\
\hline \multirow{3}{*}{ Age } & $18-$ & 72.9 & 10.5 & \multirow{3}{*}{$\begin{array}{l}\mathrm{F}=8.7 \\
.008^{*}\end{array}$} \\
\hline & $20-$ & 70.1 & 10.2 & \\
\hline & $22+$ & 69.6 & 10.1 & \\
\hline \multirow{2}{*}{ Sex } & Male & 74.1 & 9.8 & \multirow{2}{*}{$\begin{array}{l}t=5.2 \\
<.001 * \#\end{array}$} \\
\hline & Female & 69.9 & 10.3 & \\
\hline \multirow{2}{*}{ Permanent residence place } & Urban & 68.2 & 11.0 & \multirow{2}{*}{$\begin{array}{l}t=1.84 \\
<.001 * \#\end{array}$} \\
\hline & Rural & 71.1 & 10.2 & \\
\hline \multirow{3}{*}{ Previous qualification } & Secondary school certificate & 71.5 & 10.5 & \multirow{3}{*}{$\begin{array}{l}F=2.6 \\
.097\end{array}$} \\
\hline & Technical nursing diploma & 69.3 & 9.4 & \\
\hline & Others & 68.5 & 20.7 & \\
\hline \multirow{8}{*}{ Nursing specialty } & Medical-surgical nursing & 72.3 & 10.6 & \multirow{8}{*}{$\begin{array}{l}\mathrm{F}=10.9 \\
<.001^{*}\end{array}$} \\
\hline & Emergency and critical care nursing & 70.5 & 10.8 & \\
\hline & obstetrics and gynecology nursing & 68.7 & 10.6 & \\
\hline & Pediatric nursing & 73.8 & 9.2 & \\
\hline & Community health nursing & 67.8 & 9.5 & \\
\hline & Psychiatric nursing and mental health & 72.1 & 9.8 & \\
\hline & Geriatric nursing & 73.2 & 5.2 & \\
\hline & Nursing administration & 64.3 & 9.6 & \\
\hline \multirow{2}{*}{ Working during study } & Yes & 71.0 & 10.0 & $t=0.39$ \\
\hline & No & 70.8 & 10.5 & $.837 \#$ \\
\hline
\end{tabular}

Note. F: One Way ANOVA; ${ }^{*} p<.05$; \#: Students $t$-test. 
No significant difference was identified in the mean score percentages of overall nursing students' service quality perceptions among participants' previous qualifications and working during the study. The majority of nursing students $(70.1 \%)$ felt that the fifteen-week term was not appropriate The highest percentage of the students $(83.8 \%)$ stated that allocated course requirements were not fair for the fifteen weeks. Furthermore, $71.4 \%$ of participants mentioned that their curriculum was too focused on written exams, while more than one-half of nursing students $(55.8 \%)$ did not prefer oral exams. In addition, Table 4 shows that more than one-half $(58.5 \%)$ of students perceived that being a student in the Faculty of Nursing was prestigious in the community compared with $41.5 \%$ who had the opposite perception. About $61.5 \%$ of students felt happy studying at the Faculty of Nursing while the rest did not feel happy. Finally, more than three-quarters of students $(76.2 \%)$ would not accept opportunities to study at other higher educational institutions (see Table 4).

The participants identified barriers to quality services as being "limited time for the study" and "inadequate equipment for clinical training". Positive factors affecting the quality of services as perceived by the participants were "accuracy of the work", "effective communication with students", and "gaining new knowledge". Moreover, the highest scoring items among participants' recommendations to improve the quality of educational services were "give enough time for study", "updating training equipment and apparatus" (see Table 5).

Table 4. Nursing students' opinions regarding term duration, exams and faculty image

\begin{tabular}{|c|c|c|c|c|}
\hline \multirow{3}{*}{ Nursing students' opinions } & \multicolumn{4}{|c|}{ Nursing students $(\mathrm{N}=525)$} \\
\hline & \multicolumn{2}{|c|}{ Yes } & \multicolumn{2}{|c|}{ No } \\
\hline & No & $\%$ & No & $\%$ \\
\hline In your view is the fifteen-week term appropriate & 157 & 29.9 & 368 & 70.1 \\
\hline Do you think that the workload is fair for the fifteen-week term? & 85 & 16.2 & 440 & 83.8 \\
\hline Do you think our curriculum is too much oriented to written exams? & 375 & 71.4 & 150 & 28.6 \\
\hline Do you think our curriculum should include oral exams? & 232 & 44.2 & 293 & 55.8 \\
\hline Does being a student at Faculty of Nursing give you prestige in your community (i.e. your family, friends etc.)? & 307 & 58.5 & 218 & 41.5 \\
\hline Overall are you happy studying at Faculty of Nursing & 323 & 61.5 & 202 & 38.5 \\
\hline $\begin{array}{l}\text { Were you offered an opportunity to rather study at one of the other Higher Education institutions (i.e. Cairo } \\
\text { University, Ain Shams University), would you accept? }\end{array}$ & 125 & 23.8 & 400 & 76.2 \\
\hline
\end{tabular}

Table 5. Nursing students' perception of positive (facilitating) factors, barriers and recommendations for improvement of the educational services quality

\begin{tabular}{|c|c|c|c|}
\hline \multirow{2}{*}{\multicolumn{2}{|c|}{$\begin{array}{l}\text { Positive (facilitating) factors, barriers and recommendations for improvement of the educational } \\
\text { services quality }\end{array}$}} & \multicolumn{2}{|c|}{ Nursing students $(\mathrm{N}=525)$} \\
\hline & & \multirow{2}{*}{$\begin{array}{l}\text { No } \\
201\end{array}$} & \multirow{2}{*}{$\begin{array}{l}\% \\
38.3\end{array}$} \\
\hline \multirow{7}{*}{$\begin{array}{l}\text { \# Positive (facilitating) } \\
\text { factors }\end{array}$} & No response & & \\
\hline & Accuracy of work of teaching staff & 124 & 23.6 \\
\hline & Effective communication of teaching staff with students & 123 & 23.4 \\
\hline & Receive new and updated knowledge & 120 & 22.9 \\
\hline & Improved team work skill among students & 7 & 1.3 \\
\hline & Study in English & 5 & 1.0 \\
\hline & Improved nursing image & 3 & 0.6 \\
\hline \multirow{7}{*}{$\begin{array}{l}\text { \# Barriers of the educational } \\
\text { services quality }\end{array}$} & No response & 245 & 46.8 \\
\hline & Limited time for study & 148 & 28.2 \\
\hline & Inadequate equipment for clinical training & 54 & 10.3 \\
\hline & Ineffective communication between students and professors & 42 & 8.0 \\
\hline & Not enough classes for large number of students & 38 & 7.3 \\
\hline & Poor organization of groups and schedules & 8 & 1.5 \\
\hline & Lack of transportation accessibility to training area & 8 & 1.5 \\
\hline \multirow{7}{*}{$\begin{array}{l}\text { \# Recommendations for } \\
\text { improvement quality of } \\
\text { educational service }\end{array}$} & No response & 234 & 44.6 \\
\hline & Giving enough time to study & 130 & 24.8 \\
\hline & Updating training equipment and apparatus & 89 & 17.0 \\
\hline & Using new teaching methods & 30 & 5.7 \\
\hline & Good communication with students & 25 & 4.8 \\
\hline & Periodic exams & 15 & 2.9 \\
\hline & Students participation in decision making & 15 & 2.9 \\
\hline
\end{tabular}

\# Multi response questions 


\section{Discussion}

Higher educational institutions have the important goal of educating citizens who will shape the future of nations. This goal constantly competes with the obstacles created by rapidly growing and changing societies. In fulfilling their missions, Ministries and institutions of higher education have a responsibility to various stakeholders. ${ }^{[26]}$

The mean score percentage of the overall nursing students' perceptions of educational service quality was relatively high (70.9 \pm 10.3 ). This is supported by the present results which found reliability to be the highest scoring dimension followed in descending order by the assurance, empathy, responsiveness, and tangibles dimensions. Ahmed et al. (2012) ${ }^{[27]}$ also found that the highest perceived quality dimension among students was reliability followed by tangibles, responsiveness, assurance, and empathy. Likewise, Yousapronpaiboon $(2014)^{[28]}$ found that the total mean score of undergraduate students' service quality perceptions was 4.56 . Among the five dimensions, the reliability dimension once again had the highest perceptions, while the empathy dimension had the lowest.

A study conducted by Combrinck (2006) ${ }^{[29]}$ reported that students at performance management department at Western Cape University ranked the service quality dimensions from highest to lowest as follows: reliability, assurance, tangibles, responsiveness, and empathy. By comparison, Abu Hasan et al. $(2008)^{[12]}$ reported that for each dimension, assurance dimension scores were the highest followed by responsiveness, reliability, tangibility, and empathy with a 4.07 total mean score of service quality, indicating that students were somewhat satisfied with overall service quality.

In this study, the mean scores of the underlying items in the reliability dimension ranged from 3.52 to 3.94 . The highest mean scores were in response to the following items: "Academics staff are ready to provide individual attention for their students during their consultation session", "The department offers its services within the expected time", and "The department deals with queries quickly and efficiently". These scores can be further explained by the students' comments which indicated that they viewed the precision of work positively and felt that it impacted the nature of instruction. The lowest mean score was received by "Administrative staff in the department is interested in solving problem I have".

In the assurance dimension, "Academic staff has the knowledge to answer any questions that related to courses provided" and "The department allowed me to feel secure in my academic transactions" had the highest mean scores which ranged from 3.51 to 4.05 . This can be explained by students' comments regarding receiving new and updated knowledge

Published by Sciedu Press as a positive factor influencing the quality of educational services. The lowest mean score was related to "Academic staff able to understand their students' needs". Although a study done by Combrinck (2006) ${ }^{[29]}$ found, similar to the present study, that high perception scores of undergraduate students were related to "Academic staff has the required knowledge to reply on my questions in regard to the given courses", the Combrinck study showed low scores for "The department allowed me to feel secure in my academic transactions". Govender et al. (2014) ${ }^{[30]}$ also found that the highest perception scores applied to lecturer knowledge, while the living environment received the lowest scores.

The empathy dimension was represented by a single item, "Academic staff treated me in a caring way", which had a mean score of $3.59 \pm .091$. This result is similar to the Combrinck (2006) ${ }^{[29]}$ study, where the empathy dimension had a mean score of $4.15 \pm 1.36$. Yousapronpaiboon (2014) ${ }^{[28]}$ interpreted the low expectations and perceptions score of the empathy dimension as reflective of a feeble relationship between professors, staffs, and students.

The mean scores of the responsiveness dimension items ranged from 2.59 to 3.91, with the highest mean scores being for "I have confidence in academic staff who employs on this department" and "I have confidence in support staff who employs in this department" and the lowest scores being for "Academic staff are not willing to provide help for their students in the department". This result is supported by student comments which showed strong communication between the instructive staff and students to be a positive factor influencing the quality of educational service in the Faculty of Nursing. Similarly, Combrinck (2006) ${ }^{[29]}$ found that the highest perception score was given to "Administrative staff provide assistance when they were asked", and the lowest score was given to "Support staff have no willingness to provide help for their students".

The tangibles dimension received the lowest mean score percentage among the service quality dimensions. The mean scores of the underlying items ranged from 2.98 to 3.08 with the highest mean score given to "Course materials such as books, boards, data show etc. are attractive". The lowest mean score was given to "The available equipment in the department are updated". The low scores for the tangibles dimension can be explained by students' comments regarding insufficient equipment for clinical training being a negative factor influencing the quality of educational services and their recommendations that clinical training equipment be updated. Bunting \& Cloete (2004) ${ }^{[31]}$ reported that any decrease in available spending for education can significantly affect the quality of teaching, learning, and research and can 
have a negative impact on both facilities and educational resources.

For department specific questions, the mean score percentage of functional value for want satisfaction was higher than the mean score percentage for social value as perceived by nursing students. This might be related to student's high perceptions of the specialty departments' efforts to teach hands-on practical information during the program which is useful for graduating students pursuing successful careers. However, students also feel that their colleagues focus on individual achievements over teamwork.

Significant statistical differences were found in the mean score percentages of service quality perceptions for nursing students based on demographic characteristics. This study showed that the mean score percentages of service quality perceptions for nursing students in various specialty departments were higher for male students in the age group of 18 to less than 20 years studying in the specialties of pediatric, geriatric, and psychiatric and mental health nursing. Mean score percentages were lower in female students aged 22 years and older studying in the specialties of nursing administration, community health, and obstetric and gynecological nursing. These results are in line with the results of Yousapronpaiboon $(2014)^{[28]}$ who reported statistically significant differences between students' perceptions of service quality according to gender and age.

The present study found that $70.1 \%$ of nursing students felt the fifteen-week term was not appropriate, and $83.8 \%$ felt the workload was not fair for the length of the term. Furthermore, a majority of participants $(71.4 \%)$ reported that the curriculum was too focused on written exams, while $55.8 \%$ stated that oral exams should not be included in the curriculum. This result is supported by the comments of $28.2 \%$ of students overall who mentioned that the time for study was limited and suggested they be given more study time.
More than one-half of nursing students felt that the Faculty of Nursing gave them a level of prestige in the community. Additionally, about two-thirds (61.5\%) were happy to study at the Faculty of Nursing, and a high percentage of them (76.2\%) stated they would not study at a different higher educational institution even if they had an opportunity to do so. This may be because they believe that being students at Alexandria University will better prepare them for their careers and make them more desirable in the labor market. A similar result was seen in the study by Combrinck (2006) ${ }^{[29]}$ in which $72 \%$ of undergraduate students mentioned that the University of Western Cape provided students with community prestige. Additionally, a majority of undergraduate students $(83 \%)$ were happy to study there. However, unlike the present study, half of the undergraduate students studied by Combrinck (2006) ${ }^{[29]}$ felt that they would study at other universities if they could.

\section{Conclusion}

Our study demonstrates that nursing students' perceptions of service quality at different specialty nursing departments was relatively high overall. The highest perceived service quality dimension among students was reliability followed by assurance, empathy, responsiveness, and tangibility. Moreover, a majority of nursing students affirmed that the Faculty of Nursing gives them prestige in the community.

The researchers recommend periodic assessment of students' and academic staff's service quality perceptions and satisfaction to provide continuous feedback of institution performance. Based on the study results, students would feel they are receiving higher quality service if teaching equipment was kept fully stocked and up-to-date. Further, to address the responsiveness dimension, academic and support staff need to demonstrate the willingness to help students.

\section{CONFlicts OF INTEREST Disclosure}

The authors declare that there is no conflict of interest.

\section{REFERENCES}

[1] Anci DT. How satisfied are our students? Quality management unit office for institutional effectiveness University of Johannesburg, Johannesburg, South Africa. 2006. PMid:17063927

[2] DeShields OW, Kara A, Kaynak E. Determinants of business student satisfaction and retention in higher education: Applying Herzberg's two-factor theory. International Journal of Educational Management. 2005; 19(2): 128-139. https://doi.org/10.1108/0951354051 0582426

[3] O’Neill MA, Palmer A. Importance-performance analysis: a useful tool for directing continuous quality improvement in higher

education. Quality Assurance in Education. 2004; 1(1): 39-52. https ://doi.org/10.1108/09684880410517423

[4] Lovelock C, Wirtz J. Services marketing. 7th ed. New Jersey: Pearson. 2011

[5] Abdullah F. The development of HEdPERF: a new measuring instrument of service quality for the higher education sector. International Journal of Consumer Studies. 2006; 30(6): 569-581. https://doi.org/10.1111/j.1470-6431.2005.00480.x

[6] Wright C, O'Neill M. Service quality evaluation in the higher education sector: An empirical investigation of students' perceptions in higher education. Research and Development. 2003; 21(1): 23-39. 
[7] Quinn A, Lemay G, Larsen P, et al. Service quality in higher education. Total Quality Management. 2009; 20(2): 139-152. https : //doi.org/10.1080/14783360802622805

[8] O'Neill M. The role of perception in disconfirmation models of service quality. Measuring Business Excellence. 2000; 4(2): 46-59.

[9] Pariseau S, McDaniel J. Assessing service quality in schools of business. International Journal of Quality and Reliability Management. 1997; 14: 204-18. https://doi.org/10.1108/026567197101 65455

[10] Cronin J, Taylor S. Measuring service quality: A reexamination and extension. 1992; 56(3): 55-68.

[11] Tan K, Kik S. Service quality in higher education using an enhanced SERVQUAL approach. Quality in Higher Education. 2004; 10(1): 17-24. https://doi.org/10.1080/1353832242000195032

[12] Abu Hasan HF, Ilias A, Abd Rahman R, et al. Service quality and student satisfaction: A case study at private higher education institutions. International Business Research. 2008; 1(3): 163-175.

[13] De Oliveira O, Ferreira E. Adaptation and application of the SERVQUAL scale higher education. POMS 20th Annual Conference Orlando, Florida U.S.A. 2009.

[14] Legčević J. Quality gap of educational services in viewpoints of students. Ekonoska Misao Praksa DBK. GOD. 2009; 18(2): 279-298.

[15] Zeshan A, Afridi T, Khan SM. Assessing service quality in business schools: Implications for improvement. The 3rd International Conference on Assessing Quality in Higher Education. December 6-8, 2010, Lahore-Pakistan. 2010; 220-232.

[16] Khodayari F, Khodayari B. Service quality in higher education. Interdisciplinary Journal of Research in Business. 2011; 1(9): 38-46.

[17] Amelia L, Hidayanto AN, Hapsari IC. Analysis of IS/IT service quality in the higher education with SERVQUAL: A case study of STMIK MDP Palembang. The 2nd International Research Symposium in Service Management. Yogyakarta, Indonesia. 2011.

[18] Mohamad Yusof AR, Hassan Z, Abdul Rahman S, et al. Educational service quality at public higher educational institutions: A proposed framework and importance of the sub-dimensions. International Journal of Economics Business and Management Studies. 2012; 1(2): 36-49.

[19] Al-Alak BA, Al Naser ASM. Assessing the relationship between higher education service quality dimensions and student satisfaction. Australian Journal of Basic and Applied Sciences. 2012; 6(1): 156-164.
[20] Shah IA, Baporikar N. Suitability of imported curriculum for learning in GCC States: Oman perspective, teaching and learning in Arab World. Peter Lang Publishing Group, Bern, Berlin, Bruxelles, Frankfurt am Main, New York, Oxford, Wien. 2010.

[21] Atteh SO. The crisis in higher education in Africa. Journal of Opinion. 1996; 24(1): 36-42.

[22] Salmi J. The higher education crisis in developing countries: Issues, problems, constraints and reforms. International Review of Education. 1992; 32(1): 19-33. https://doi .org/10.1007/BF01097942

[23] Human Rights Watch. Reading Between the 'Red Lines: The repression of academic freedom in Egyptian Universities. 2005. Available from: https://searchworks.stanford.edu/view/5981074

[24] Shann M. The reform of higher education in Egypt. Higher Education. 1992; 24(2): 225-246. https ://doi.org/10.1007/BF00129443

[25] Ghazal R. Major issues in Egyptian higher education: Reflections of an Egyptian student. Comparative and International Higher Education. 2012; 4: 19-21.

[26] Freeman I, Thomas M. Consumerism in education: A comparison between Canada and the United Kingdom. International Journal of Management Education. 2005; 19(2): 153-177. https://doi.or $\mathrm{g} / 10.1108 / 09513540510582444$

[27] Ahmed I, Ismail W, Amin S, et al. In the quest of excellence: Significance of Quality for students, teachers, and institution. International Journal of Academic Research. 2012; 4(1): 148-153.

[28] Yousapronpaiboon K. SERVQUAL: Measuring higher education service quality in Thailand. Social and Behavioral Sciences. 2014; 116 1088-1095. https://doi .org/10.1016/j.sbspro.2014.01.3 50

[29] Combrinck T. A pilot empirical investigation into student perceptions of service quality at the department of management of the university of the Western Cape. A research project in partial fulfillment of the requirements for the degree of Master of Commerce. Faculty of Economic and Management Sciences. University of the Western Cape. 2006.

[30] Govender J, Veerasamy D, Noel D. The service quality experience of international students: The case of a selected higher education institution in South Africa. Mediterranean Journal of Social Sciences. 2014; 5(8): 465-473

[31] Bunting I, Cloete N. Approaches to measuring performance in higher education: A South African case study. Draft Discussion Paper. Council on Higher Education Policy/Change Dialogue. Cape Town. 9 March 2004. 